\title{
Community-associated methicillin-resistant Staphylococcus aureus: prevalence in skin and soft tissue infections at emergency departments in the Greater Toronto Area and associated risk factors
}

\author{
Heather J. Adam, PhD; ${ }^{*}$ Vanessa G. Allen, MD; ${ }^{*}$ Andrea Currie, MHSc; ${ }^{\dagger}$ Allison J. McGeer, MD; ${ }^{* \neq}$ \\ Andrew E. Simor, MD; ${ }^{* \S}$ Susan E. Richardson, MD; ${ }^{*}$ L Lisa Louie, ART; ${ }^{\S}$ Barbara Willey, ART; $;$ \\ Tim Rutledge, $\mathrm{MD}_{;}^{\dagger}$ Jacques Lee, MD; ${ }^{\S}$ Ran D. Goldman, MD; ${ }^{* *}$ Andrea Somers, MD; ${ }^{\dagger \dagger}$ \\ Paul Ellis, MD; ${ }^{\dagger \dagger}$ Alicia Sarabia, MD; $;{ }^{\ddagger \ddagger}$ John Rizos, MD; ${ }^{\ddagger \ddagger}$ Bjug Borgundvaag, MD; \\ Kevin C. Katz, MD; ${ }^{*}{ }^{\S \S}$ for the EMERGENTWorking Group
}

See related articles on pages 417 and 430

\section{ABSTRACT}

Objective: Community-associated methicillin-resistant Staphylococcus aureus (CA-MRSA), which is caused primarily by the Canadian methicillin-resistant Staphylococcus aureus-10 (CMRSA-10) strain (also known as the USA300 strain) has emerged rapidly in the United States and is now emerging in Canada. We assessed the prevalence, risk factors, microbiological characteristics and outcomes of CAMRSA in patients with purulent skin and soft tissue infections (SSTIs) presenting to emergency departments (EDs) in the Greater Toronto Area.

Methods: Patients with Staphylococcus aureus SSTIs who presented to 7 EDs between Mar. 1 and Jun. 30, 2007, were eligible for inclusion in this study. Antimicrobial susceptibilities and molecular characteristics of MRSA strains were identified. Demographic, risk factor and clinical data were collected through telephone interviews.

Results: MRSA was isolated from 58 (19\%) of 299 eligible patients. CMRSA-10 was identified at 6 of the 7 study sites and accounted for 29 (50\%) of all cases of MRSA. Telephone interviews were completed for 161 of the eligible patients. Individuals with CMRSA-10 were younger (median $34 \mathrm{v}$. $63 \mathrm{yr}, p=0.002$ ), less likely to report recent antibiotic use ( $22 \%$ v. $67 \%, p=0.046$ ) or health care-related risk factors (33\% v. $72 \%, p=0.097$ ) and more likely to report community- related risk factors $(56 \%$ v. $6 \%, p=0.008)$ than patients with other MRSA strains. CMRSA-10 SSTIs were treated with incision and drainage ( 1 patient), antibiotic therapy (3 patients) or both (5 patients), and all resolved. CMRSA-10 isolates were susceptible to clindamycin, tetracycline and trimethoprimsulfamethoxazole.

Conclusion: CA-MRSA is a significant cause of SSTIs in the Greater Toronto Area, and can affect patients without known community-related risk factors. The changing epidemiology of CA-MRSA necessitates further surveillance to inform prevention strategies and empiric treatment guidelines.

Keywords: Staphylococcus aureus, methicillin resistance, community-associated infections, risk factors, skin diseases and infections, soft tissue infections

\section{RÉSUMÉ}

Objectif : L'infection à Staphylococcus aureus résistant à la méthicilline d'origine communautaire (SARM-C), qui est attribuable principalement à la souche canadienne du Staphylococcus aureus résistant à la méthicilline-10 (SARMC10), également connu sous le nom de souche USA300, a connu une éclosion rapide aux États-Unis et est en train d'émerger au Canada. Nous avons évalué la prévalence, les facteurs de risque, les caractéristiques microbiologiques et le

From the *Department of Laboratory Medicine and Pathobiology, Faculty of Medicine, University of Toronto, Toronto, Ont., the tDepartments of Infection Prevention and Control and Emergency Medicine, North York General Hospital, North York, Ont., the ¥Departments of Emergency Medicine and Microbiology, Mount Sinai Hospital, Toronto, Ont., the §Departments of Microbiology and Emergency Medicine, Sunnybrook Health Sciences Centre, Toronto, Ont., the IDivision of Microbiology, Department of Paediatric Laboratory Medicine, Hospital for Sick Children, Toronto, Ont., the **Department of Emergency Medicine, Vancouver Children's Hospital, Vancouver, BC, the ††Department of Emergency Medicine, University Health Network, Toronto, Ont., the $\ddagger$ Departments of Microbiology and Emergency Medicine, Credit Valley Hospital; Toronto, Ont., and the §§Department of Laboratory Medicine, North York General Hospital; North York, Ont.

Submitted Jun. 24, 2008; Revised Jan. 26, 2009; Accepted Jan. 31, 2009

This article has been peer reviewed.

CJEM 2009;11(5):439-46 
devenir des patients infectés par SARM-C qui se présentent dans les urgences du Grand Toronto avec des infections de la peau et des tissus mous (IPTM) purulentes.

Méthode : Les patients présentant des IPTM à Staphylococcus aureus qui se sont rendus dans un des 7 services d'urgence, entre le 1er mars et le 30 juin 2007 étaient admissibles à l'étude. On a déterminé la susceptibilité antimicrobienne et les caractéristiques moléculaires des souches de SARM. On a recueilli des données démographiques et cliniques ainsi que des données sur les facteurs de risque par entretiens téléphoniques.

Résultats : On a isolé le SARM chez 58 (19\%) des 299 patients admissibles. Le SARM-10 a été identifié dans 6 des 7 emplacements participants à I'étude. II représentait 29 (50\%) de tous les cas d'infection à SARM. Des entretiens téléphoniques ont été réalisés auprès de 161 des patients admissibles. Les patients infectés à SARMC-10 étaient plus jeunes (médiane de 34 contre 63 ans, $p=0,002$ ), moins susceptibles de signaler I'utilisation récente d'antibiotiques (22\% contre $67 \%, p=0,046)$ ou des facteurs de risque associés aux soins de santé (33\% contre $72 \%, p=0,097)$ et plus susceptibles de déclarer des facteurs de risque associés à la collectivité (56\% contre $6 \%, p=0,008$ ) que les patients infectés par d'autres souches du SARM. Les IPTM à SARMC-10 ont été traités par incision et drainage ( 1 patient), par antibiothérapie ( 3 patients) ou les deux (5 patients) et se sont toutes résorbées. Les isolats de SARMC-10 étaient sensibles à la clindamycine, à la tétracycline et au triméthoprime-sulfaméthoxazole.

Conclusion : Le SARM-C est une cause importante d'IPTM dans la région du Grand Toronto, et peut s'attaquer aux patients sans facteurs de risque associés à la collectivité. L'évolution de l'épidémiologie du SARM-C nécessite une plus grande surveillance pour guider I'élaboration de stratégies préventives et de lignes directrices relatives au traitement empirique de ces infections.

\section{INTRODUCTION}

In the past, methicillin-resistant Staphylococcus aureus (MRSA) was almost exclusively a nosocomial pathogen. Over the last decade, it has emerged in community settings causing skin and soft tissue infections (SSTIs), necrotizing pneumonia, necrotizing fasciitis and sepsis. ${ }^{1}$ In the United States, community-associated MRSA (CA-MRSA) was first observed in marginalized populations and, in general, under conditions of close physical contact, overcrowding and poor hygiene. ${ }^{2-10}$ Now, CAMRSA is reported as the most common cause of purulent SSTIs in many centres in the United States. ${ }^{4,11,12}$ Recent reports from various centres in the United States have shown that Staphylococcus aureus (S. aureus) accounts for nearly $75 \%$ of these infections, with CAMRSA strains predominating. ${ }^{4,11,12}$

CA-MRSA is emerging in Canada. Outbreaks of CA-MRSA have been described in at-risk populations in recent years ${ }^{13-15}$ and there have been anecdotal reports of MRSA infection in individuals without risk factors. The hospital-based Canadian Nosocomial Surveillance Program reported that $15 \%$ of MRSA infections in 2006 were acquired in the community, but this program only surveys inpatients. ${ }^{16}$ Broader population surveillance has been identified as a priority to increase our understanding of CA-MRSA in Canada. ${ }^{1}$

In Canada the rise of CA-MRSA is primarily due to the epidemic strain Canadian methicillin-resistant Staphylococcus aureus-10 (CMRSA-10) (equivalent to USA300 in the United States). CMRSA-10 has unique microbiological properties relative to hospital-associated MRSA strains including the presence of the staphylococcal chromosomal cassette mec (SCCmec) type IV, the frequent presence of Panton-Valentine leukocidin (PVL) genetic determinant and increased susceptibility to non- $\beta$-lactam antibiotics. ${ }^{17-19}$ As the strain primarily responsible for the rapid emergence of CA-MRSA, CMRSA-10 can be used to monitor the changing epidemiology of MRSA and to develop CA-MRSA prevention and treatment strategies.

The goal of this study is to determine the current prevalence, associated risk factors, microbiological characteristics and treatment outcomes of CA-MRSA in patients with purulent SSTIs presenting to emergency departments (EDs) in the Greater Toronto Area.

\section{METHODS}

\section{Study population}

This study was conducted between Mar. 1 and Jun. 30, 2007, in the ED of 7 hospitals in the Greater Toronto Area (combined volume of 350000 patient visits annually). The 7 hospitals serve a variety of patient populations and include adult inner-city hospitals (hospitals 1, 2 and 3), a pediatric referral centre (hospital 4), an urban academic hospital near the city core (hospital 5), and community hospitals providing both pediatric and adult emergency care (hospitals 6 and 7).

The triage nurse at each centre informed all eligible patients presenting with SSTIs that they would be contacted by telephone and asked to consent to participate in the study if eligible. Study information brochures containing investigator contact information and posters were placed at each site.

Emergency physicians were asked to swab the single largest area of infection of each patient with a purulent 
SSTI. During the study period, patients were managed according to usual practice at the discretion of the treating physician. The ED charts at 1 participating hospital were reviewed for the entire study period to assess the proportion of SSTI patients from whom wound swabs were collected.

\section{Patient enrolment process}

Eligible participants were identified based on the microbiological classification of cultures obtained from wound swabs. Only patients with $S$. aureus-positive cultures obtained in the ED were eligible for inclusion. Following the identification of S. aureus, each laboratory forwarded the patient demographics and contact information to study staff, who telephoned patients for consent to participate.

\section{Patient interviews}

With the exception of age and sex, patient information for this study was obtained by standardized telephone interviews. Patients with laboratory-confirmed $S$. aureus infections were contacted at least 2 weeks after their ED visit. Trained interviewers made 15 attempts to reach each patient on different days and times, including evenings and weekends. The study questionnaire addressed demographics, clinical presentation including predisposing skin breaks, risk factors for communityand hospital-associated MRSA infections, treatment and outcome. ${ }^{1,12}$ The specific risk factors included in the questionnaire are detailed in Table 1. Patients were also asked if they could recall receiving advice from ED staff about preventing the spread of skin infections.

Consenting patients with MRSA were also contacted at least 3 months after their index visit and asked about the outcome of their initial infection, recurrent infections and transmission to household or family members. Patients who were initially contacted 75 days or more after their visit to the ED were not contacted again for follow-up at 3 months.

This study was conducted in compliance with the Personal Health Information Protection Act and was approved by the research ethics board at each hospital.

\section{Laboratory methods}

The laboratories at participating sites identified S. aureus from wound specimens using conventional methodologies, including colony morphology, gram stain morphology, catalase test, Pastorex Staph Plus latex agglutination (Bio-Rad Laboratories) and tube coagulase test.

Based on the individual laboratory's standard protocols, methicillin susceptibility was determined using 1 or more of the following methods: oxacillin screen plates (Mueller-Hinton agar with $4 \%$ sodium chloride

Table 1. Comparison of risk factors among enrolled patients with purulent skin and soft tissue infections caused by methicillin-susceptible Staphylococcus aureus, methicillin-resistant Staphylococcus aureus and the prototypical community-associated methicillin-resistant Staphylococcus aureus strain

\begin{tabular}{|c|c|c|c|c|c|c|}
\hline \multirow[b]{2}{*}{ Risk factor } & \multicolumn{2}{|c|}{ No. (\%) of patients } & \multirow[b]{2}{*}{$p$ value* } & \multicolumn{2}{|c|}{ No. (\%) of patients } & \multirow[b]{2}{*}{$p$ value* } \\
\hline & $\begin{array}{l}\text { MSSA } \\
n=134\end{array}$ & $\begin{array}{c}\text { MRSA } \\
n=17\end{array}$ & & $\begin{array}{c}\text { CMRSA-10 } \\
n=9\end{array}$ & $\begin{array}{c}\text { Other MRSA } \\
\text { strains, } n=18\end{array}$ & \\
\hline Antibiotics in previous 3 months & $38(28)$ & $14(52)$ & 0.02 & $2(22)$ & $12(67)$ & 0.05 \\
\hline Known exposure to MRSAt & $4 \quad(3)$ & $11(41)$ & $<0.001$ & $2(22)$ & $9(50)$ & 0.21 \\
\hline Direct health care-related risk factor $\neq$ & $63(47)$ & $16(59)$ & 0.26 & $3(33)$ & $13(72)$ & 0.10 \\
\hline Indirect health care-related risk factor§ & $59(44)$ & $9(33)$ & 0.31 & $3(33)$ & $6(33)$ & 1.00 \\
\hline Community risk factor $\mathbb{9}$ & 39 (29) & $6(22)$ & 0.47 & $5(56)$ & $1 \quad(6)$ & 0.01 \\
\hline Travel to United States in previous year & $35(26)$ & $7(26)$ & 0.95 & $3(33)$ & $4(22)$ & 0.65 \\
\hline Chronic skin condition & $30(22)$ & $6(22)$ & 0.97 & $1(11)$ & $5(28)$ & 0.63 \\
\hline \multicolumn{7}{|c|}{$\begin{array}{l}\text { CMRSA-10 = Canadian methicillin-resistant Staphylococcus aureus-10; MRSA = methicillin-resistant Staphylococcus aureus; MSSA = methicillin-susceptible Staphylococcus } \\
\text { aureus. } \\
{ }^{*} \chi^{2} \text { test or, where cell counts < } 5 \text {, Fisher exact } 2 \times 2 \text { test for a difference in proportions (e.g., proportion of patients with MSSA versus the proportion of patients with MRSA } \\
\text { who reported the risk factor). } \\
\text { thnown exposure to MRSA: patient or household/family member with history of MRSA colonization or infection. } \\
\text { fDirect health care-related risk factor included any } 1 \text { of the following: health care worker/volunteer; admitted to hospital overnight or resident of a long-term care facility in } \\
\text { previous year; receiving dialysis; urinary catheter; intravenous line; surgery in previous } 6 \text { months. } \\
\text { SIndirect health care-related risk factor included any } 1 \text { of the following: household or family member admitted to hospital overnight in previous year; household or family } \\
\text { member is a health care worker; regular visit to long-term care facility in previous year. } \\
\text { ICommunity risk factor included any } 1 \text { of the following: lived in shelter, military barracks, correctional facility or other group setting in the previous year; had regular contact } \\
\text { with somene who lives in a shelter, is homeless, uses intravenous drugs, is HIV-positive, is a member of the gay/lesbian/bisexual community; participation in group or contact } \\
\text { sports. (Other group settings reported by patients with MRSA included hostel, rehabilitation centre and subsidized housing, and by patients with MSSA included rooming } \\
\text { house, foster home, palliative care centre and recreational and educational facilities). }\end{array}$} \\
\hline
\end{tabular}


and $6 \mu \mathrm{g} / \mathrm{mL}$ oxacillin) or cefoxitin disk diffusion and/or detection of penicillin-binding protein 2a (MRSAScreen, Oxoid, Ltd.). MRSA isolates were forwarded to a central laboratory and susceptibilities were determined by broth microdilution using Clinical and Laboratory Standards Institute (CLSI) protocols. ${ }^{20,21}$ Published interpretative criteria were used to determine the susceptibility of fusidic acid and mupirocin, as CLSI breakpoints have not been established. ${ }^{22,23}$ Inducible clindamycin resistance was tested by double disk diffusion in accordance with the CLSI protocols. ${ }^{21}$

Pulsed field gel electrophoresis was performed using the Canadian standardized S. aureus protocol and classified by Canadian MRSA epidemic strain nomenclature. ${ }^{24}$ MRSA isolates were tested at a reference laboratory for the presence of PVL by polymerase chain reaction. ${ }^{25}$ SCCmec typing (I-IV) was conducted using a previously described multiplex polymerase chain reaction. ${ }^{26,27}$

For our study, CA-MRSA was defined by isolating MRSA with the CMRSA-10 pulsed field gel electrophoresis pattern, which is consistent with the observation that this is the predominant clone associated with the emergence of CA-MRSA in Canada and the United States. ${ }^{1,12}$ The pulsed field gel electrophoresis pattern is

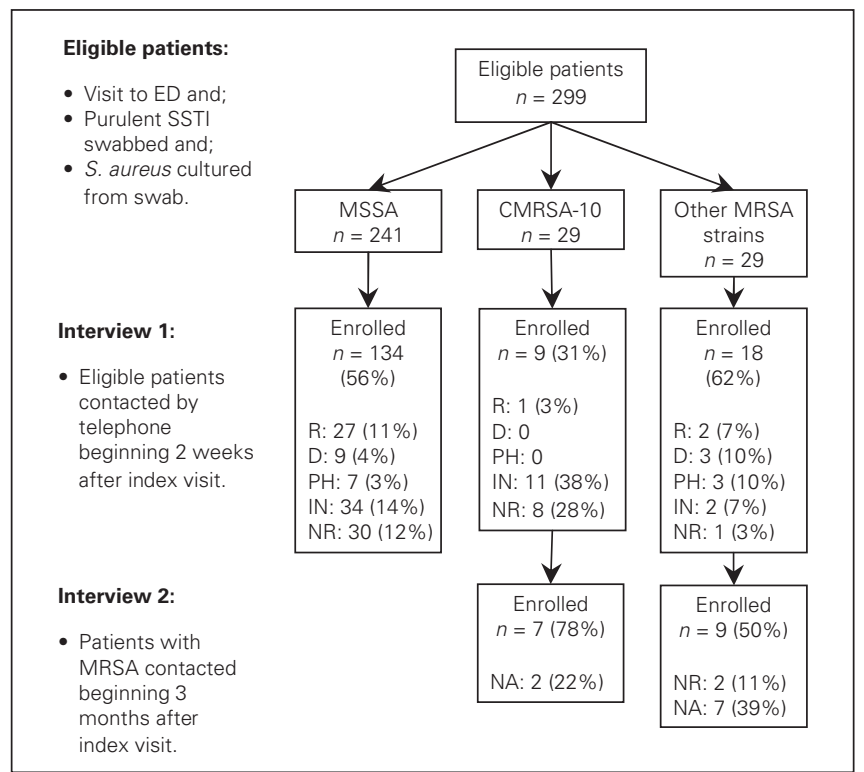

Fig. 1. Flow diagram detailing patient enrolment subsequent to the identification of Staphylococcus aureus (S. aureus) in samples from purulent skin and soft tissue infections (SSTIs) collected in the emergency department (ED). $D=$ deceased; IN = invalid telephone number in laboratory database; $N A=$ no attempt made since could not reach patient for interview 1 until $\geq 75$ days after the patient's visit to the $\mathrm{ED} ; \mathrm{NR}=$ not able to reach after 15 attempts; $\mathrm{PH}=$ unable to participate due to poor health status; $\mathrm{R}=$ refused. currently the most useful microbiological determinant of CA-MRSA because other genetic determinants such as PVL have been detected in both methicillin-susceptible Stapbylococcus aureus (MSSA) and other MRSA clones. ${ }^{1,12}$

\section{Statistical analysis}

Data were managed using EpiData (version 3.1, The EpiData Association) and analyzed using SAS statistical software (version 9.1, SAS Institute Inc.). Descriptive statistics were used to describe patient characteristics and the prevalence of MRSA in the study population. Demographics and risk factor frequencies were compared between patients grouped by methicillin susceptibility (MSSA compared with MRSA) and MRSA strain type (CMRSA-10 compared with other MRSA strains) using the $\chi^{2}$ test, Fisher exact test and Student $t$ test when appropriate.

\section{RESULTS}

During the 4-month study period, $S$. aureus was isolated from 299 ED patients with purulent SSTIs (Fig. 1). Among these eligible patients, the overall prevalence of MRSA was $19 \%$ (58 of 299 isolates) and averaged $17 \%$ by study site (range 6\%-26\%). CMRSA-10 was the most common strain type comprising $29(50 \%)$ of the 58 MRSA isolates overall and a median of $25 \%$ of MRSA isolates by study site (range $0 \%-85 \%$ ) (Table 2). Of the remaining isolates, 14 were CMRSA-2, 5 were CMRSA4 , there was 1 isolate each of CMRSA-1, -5, -6, -7, -8 and -9 , and there were 4 isolates with patterns other

\begin{tabular}{|c|c|c|c|c|c|}
\hline \multirow{2}{*}{$\begin{array}{l}\text { Hospital } \\
1\end{array}$} & \multirow{2}{*}{$\begin{array}{l}\text { No. of } \\
\text { patients with } \\
\begin{array}{c}\text { S. aureus } \\
\text { isolated }\end{array} \\
86\end{array}$} & \multicolumn{2}{|c|}{$\begin{array}{c}\% \text { of } S \text {. aureus } \\
\text { isolates that were } \\
\text { MRSA }(95 \% \mathrm{Cl})\end{array}$} & \multicolumn{2}{|c|}{$\begin{array}{c}\% \text { of MRSA isolates } \\
\text { that were CMRSA- } \\
10(95 \% \mathrm{Cl})\end{array}$} \\
\hline & & 23 & $(14-32)$ & 85 & $(69-100)$ \\
\hline 2 & 37 & 11 & $(1-21)$ & 25 & (0-67) \\
\hline 3 & 42 & 26 & (13-39) & 36 & (8-65) \\
\hline 4 & 16 & 6 & (0-18) & 0 & - \\
\hline 5 & 24 & 17 & $(2-32)$ & 25 & $(0-67)$ \\
\hline 6 & 48 & 25 & $(13-37)$ & 42 & $(14-70)$ \\
\hline 7 & 46 & 13 & (3-23) & 17 & $(0-46)$ \\
\hline Total & 299 & 19 & $(15-24)$ & 50 & (37-63) \\
\hline
\end{tabular}

$\mathrm{Cl}=$ confidence interval; $\mathrm{CMRSA}-10=$ Canadian methicillin-resistant Staphylococcus aureus-10; MRSA = methicillin-resistant Staphylococcus aureus; MSSA = methicillinsusceptible Staphylococcus aureus; $S$. aureus = Staphylococcus aureus. 
than CMRSA-1-10. The highest proportion of CMRSA-10 (85\%) was in Hospital 1, an inner-city hospital with rare pediatric visits. The hospital with the lowest proportion of MRSA and no CMRSA-10 was Hospital 4, the pediatric referral hospital in the city centre. Based on review of ED charts at Hospital 1 during the study period, $99(87 \%)$ of 114 patients with a SSTI presentation had a culture swab collected.

Age and sex distributions of eligible patients with MRSA were similar to those with MSSA (Table 3). Eligible patients with CMRSA-10 were significantly younger than patients with other MRSA strains $(p<0.001)$.

A total of 161 patients (134 patients with MSSA and 27 patients with MRSA) could be contacted and consented to telephone interviews. Overall, interviewed patients were younger (mean age 45, standard deviation [SD] 25, yr v. $51, \mathrm{SD} 24, \mathrm{yr} ; p=0.045$ ) and slightly less likely to be male $(54 \%$ v. $64 \% ; p=0.08)$ than patients not enrolled.

Table 1 shows the characteristics of the 161 interviewed patients. Patients with MRSA were more likely to report antibiotic use in the previous 3 months $(52 \% \mathrm{v}$. $28 \%, p=0.020)$ and to have had known MRSA exposures $(41 \%$ v. $3 \%, p<0.001)$ but were similar to patients with MSSA in all other risk factors examined. In contrast, CMRSA-10 patients reported known communityrelated risk factors for MRSA more often than patients with other MRSA strains $(56 \%$ v. $6 \%, p=0.008)$, and health care-related risk factors or recent antibiotic use less often. Four of 9 patients with CMRSA-10 did not report any community-related risk factors. However, 2 of these 4 patients reported direct health care-related risk factors and 1 additional patient reported visiting a MRSA-colonized family member in hospital.

The clinical presentations, treatment and outcomes of the enrolled patients are detailed in Table 4. The 9 interviewed patients with CMRSA-10 SSTIs all had resolved or improved by the first interview at a median of 28 days after the visit to the ED. Of the 7 patients with CMRSA-10 who completed follow-up interviews, 4 reported recurrent skin infections that had since resolved with additional treatment. In contrast, 5 (28\%) of 18 SSTIs due to other MRSA strains had not improved or resolved at the time of the first interview conducted at a median of 45 days after the ED visit. At the 3-month follow-up for the 9 patients with other MRSA strains, none had recurrent infections and only 1 patient, with a surgical site infection, reported their initial infection had not resolved or improved.

Only one-third $(31 \%)$ of 161 interviewed patients recalled receiving advice about how to prevent the spread of skin infections. Most frequently, patients recalled being advised to practise hand hygiene (10\%), keep the infection covered (9\%), and avoid sharing personal items such as towels (3\%).

All CMRSA-10 isolates contained SCCmec IVa and were positive for the PVL gene. There were 9 other MRSA isolates that contained the SCCmec IVc cassette of which 6 were also PVL positive. The remaining 17 of $29(59 \%)$ of the isolates contained SCCmec II. Unlike other MRSA strains, all CMRSA-10 isolates were susceptible to trimethoprim-sulfamethoxazole, clindamycin, tetracycline, doxycycline, and gentamicin (Table 5).

\section{DISCUSSION}

CA-MRSA initially appeared in the United States as localized community outbreaks, but has since become widespread in community and health care settings. ${ }^{12,28} \mathrm{~A}$

\begin{tabular}{|c|c|c|c|c|c|c|c|}
\hline \multirow[b]{2}{*}{ Demographics } & \multicolumn{3}{|c|}{ No. (\%) of patients } & \multirow[b]{2}{*}{$p$ value* } & \multicolumn{2}{|c|}{ No. (\%) of patients } & \multirow[b]{2}{*}{$p$ value ${ }^{*}$} \\
\hline & MSSA, & $n=241$ & MRSA, $n=58$ & & CMRSA-10, $n=29$ & $\begin{array}{c}\text { Other MRSA strains, } \\
\qquad n=29\end{array}$ & \\
\hline Male & 136 & (56) & $29(50)$ & 0.53 & $16(55)$ & $13(45)$ & 0.20 \\
\hline Age group, yr & & & & 0.39 & & & $<0.001$ \\
\hline $0-4$ & 15 & (7) & $3 \quad(5)$ & & $0-$ & $3(10)$ & \\
\hline $5-19$ & 16 & (7) & $1 \quad(2)$ & & $0-$ & $1 \quad$ (3) & \\
\hline 20-39 & 62 & (26) & 21 (36) & & $17(59)$ & $4(14)$ & \\
\hline $40-59$ & 64 & $(27)$ & $16(28)$ & & 11 (38) & $5(17)$ & \\
\hline$\geq 60$ & 84 & (35) & 17 (29) & & $1 \quad(3)$ & $16(55)$ & \\
\hline
\end{tabular}


similar pattern is emerging in Canada with outbreaks in high-risk populations reported in some provinces. ${ }^{13-15}$ We observed that a substantial proportion of $S$. aureus isolates from purulent SSTI specimens obtained from 7 high-volume EDs in metropolitan Toronto were MRSA (19\%). Moreover, CMRSA-10 accounted for $50 \%$ of these MRSA isolates and was identified at all but 1 of the study sites.

Although the majority of patients with CMRSA-10 had known community-related risk factors for CAMRSA, some may have acquired this strain after contact with the health care system. In our patients, a report of hospital-associated risk factors did not rule out infection with CA-MRSA. The occurrence of CA-MRSA outside traditionally identified high-risk groups has implications for relying on risk factor screening for the diagnosis and empiric treatment of CA-MRSA.

A large number of the patients in this study received both antibiotic therapy and incision and drainage as treatment for their SSTI. Several studies have demonstrated that incision and drainage without antibiotic therapy may be sufficient for minor SSTIs. ${ }^{29,30}$ The situations in which antibiotics are necessary for the resolution of SSTIs remain unclear. The need for antibiotic therapy is an important question, as overuse of these medications is a key contributing factor to the development of resistant organisms like MRSA. When antibiotics are indicated, knowledge of the antibiotic susceptibility patterns of circulating strains is essential. In settings where MRSA prevalence is low, empiric treatment with a $\beta$-lactam antibiotic with activity against $S$. aureus may be appropriate. In our city, the prevalence of methicillin-resistance in staphylococcal SSTIs was $19 \%$, which may require physicians to reconsider their empiric therapy given the suggestion that a prevalence above $10 \%-15 \%$ warrants re-evaluation.

\begin{tabular}{|c|c|c|c|}
\hline \multirow[b]{2}{*}{ Antibiotic } & \multicolumn{3}{|c|}{$\begin{array}{c}\text { No. }(\%) \text { of resistant isolates by type of } \\
\text { MRSA strain }\end{array}$} \\
\hline & $\begin{array}{c}\text { CMRSA-10 } \\
n=29\end{array}$ & $\begin{array}{l}\text { Other MRSA } \\
\text { strains, } \\
n=29\end{array}$ & $\begin{array}{l}\text { All MRSA } \\
\text { isolates, } \\
n=58\end{array}$ \\
\hline Ciprofloxacin & $22(76)$ & $19(66)$ & 41 (71) \\
\hline Clindamycin & 0 & $21(72)$ & $21(36)$ \\
\hline Doxycycline & 0 & 2 (7) & 2 (3) \\
\hline Erythromycin & 27 (93) & $22(76)$ & 49 (85) \\
\hline Fusidic acid & 0 & $3(10)$ & 3 (5) \\
\hline Gentamicin & 0 & $4(14)$ & $4 \quad(7)$ \\
\hline Mupirocin & 0 & $3(10)$ & 3 (5) \\
\hline Tetracycline & 0 & $3(10)$ & 3 (5) \\
\hline $\begin{array}{l}\text { Trimethoprim/ } \\
\text { sulfamethoxazole }\end{array}$ & 0 & 2 (7) & 2 (3) \\
\hline \multicolumn{4}{|c|}{$\begin{array}{l}\text { CMRSA-10 = Canadian methicillin-resistant Staphylococcus aureus-10; MRSA = } \\
\text { methicillin-resistant Staphylococcus aureus. } \\
\text { Note: all isolates were susceptible to dalbavacin, daptomycin, linezolid, minocycline, } \\
\text { tigecycline, quinupristin/dalfopristin, rifampin, and vancomycin. }\end{array}$} \\
\hline
\end{tabular}

Table 4. Comparison of clinical presentation, treatment and outcomes among enrolled patients with purulent skin and soft tissue infections caused by methicillin-susceptible Staphylococcus aureus, methicillin-resistant Staphylococcus aureus and the prototypical community-associated Staphylococcus aureus strain

\begin{tabular}{|c|c|c|c|c|c|c|c|c|}
\hline \multirow[b]{2}{*}{ Clinical feature } & \multicolumn{2}{|c|}{ No. (\%) of patients } & \multirow[b]{2}{*}{$p$ value* } & \multicolumn{4}{|c|}{ No. (\%) of patients } & \multirow[b]{2}{*}{$p$ value* } \\
\hline & $\begin{array}{l}\text { MSSA } \\
n=134\end{array}$ & $\begin{array}{l}\text { MRSA, } \\
n=27\end{array}$ & & $\begin{array}{l}\mathrm{CM} \\
10\end{array}$ & $\begin{array}{l}3 S A- \\
=9\end{array}$ & $\begin{array}{l}\text { Othe } \\
\text { strain }\end{array}$ & $\begin{array}{l}\text { MRSA } \\
n=18\end{array}$ & \\
\hline \multicolumn{9}{|l|}{ Clinical presentation } \\
\hline Skin break or injury preceded infection & 86 (64) & $16(59)$ & 0.63 & 4 & (44) & 12 & (67) & 0.41 \\
\hline Febrile at emergency department presentation & $51 \quad(38)$ & $9(33)$ & 0.64 & 1 & $(11)$ & 8 & (44) & 0.19 \\
\hline \multicolumn{9}{|l|}{ Treatment } \\
\hline Incision and drainage alone & $10 \quad(8)$ & $3(11)$ & & 1 & $(11)$ & 2 & $(11)$ & \\
\hline Antibiotics alone & 59 (44) & $10(37)$ & & 3 & (33) & 7 & (39) & \\
\hline Both incision and drainage and antibiotics & 45 (34) & $11(41)$ & 0.73 & 5 & $(56)$ & 6 & (33) & 0.79 \\
\hline No treatment & $9 \quad(7)$ & $2(7)$ & & 0 & & 2 & $(11)$ & \\
\hline Resolved/improved by time of initial interview & 115 (86) & $22(82)$ & 0.56 & 9 & $(100)$ & 13 & $(72)$ & 0.14 \\
\hline Recurrent infection before follow-up interview $\dagger$ & & & & $4 \dagger$ & (44) & $0+$ & & 0.02 \\
\hline $\begin{array}{l}\text { Transmission to family/household contacts before } \\
\text { follow-up interviewt }\end{array}$ & & & & $0+$ & & $0+$ & & 1.00 \\
\hline
\end{tabular}


All CMRSA-10 isolates in this study were susceptible to oral agents including clindamycin, trimethoprimsulfamethoxazole, tetracycline and to parenteral agents including vancomycin and tigecycline. In patients with community-related risk factors and no health carerelated risk factors for MRSA, these may be appropriate empiric choices when deemed necessary. In all other patients, the appropriate oral antibiotic choice is less clear since infections may be due to more antibioticresistant strains of MRSA.

Few patients in this study recalled receiving advice from ED staff about how to prevent the spread of skin infections. To limit or prevent the widespread dissemination of CMRSA-10 in Canada, additional patient education and other control efforts are needed. Patients with SSTIs should be advised to cover their wound, to not share personal items such as razors, towels or sports equipment, to launder their clothes and linens frequently, to wash sports equipment after use and to practise frequent hand hygiene. ${ }^{1}$ If community outbreaks of MRSA are suspected, public health authorities should be notified promptly.

Continued surveillance for MRSA in Canada, including strain typing, is warranted and EDs provide valuable sentinel sites. CA-MRSA strains can spread readily in the general population and may develop resistance to additional antimicrobial agents including clindamycin, mupirocin and tetracycline as recently reported in certain settings in the United States. ${ }^{31}$ Surveillance data are therefore needed to monitor the changing prevalence, epidemiology and susceptibility profiles of CA-MRSA strains in order to determine empiric treatment guidelines and prevention strategies.

Emergency departments are at the front line of clinical medicine and provide ideal settings for detecting and monitoring new disease trends. The creation of an emergency-based surveillance system in Canada would enable real-time monitoring of emerging infections, including CA-MRSA. ${ }^{32}$ A prospective cross-Canada study on CA-MRSA prevalence is currently being undertaken through a collaboration of this working group and the Canadian Association of Emergency Physicians-Research Consortium.

\section{Limitations}

The primary limitation of this study was the lack of overall SSTI denominator. Although an audit conducted at one hospital indicated that physicians swabbed the majority of eligible patients, these data were not available at all study sites, which prohibited the determination of the overall prevalence of MRSA and CA-MRSA in ED patients presenting with purulent SSTIs. Additionally, the estimates reported may have been influenced by patterns of specimen collection by different physicians at different sites. We were also unable to capture the number of patients presenting with SSTIs caused by non-S. aureus organisms. A second limitation was the low enrolment for the telephone interview among eligible persons. Future studies should include ED chart reviews to obtain data for nonresponders and patients with no fixed address when possible. Finally, the results of this study may not be applicable to other Canadian cities. Outbreaks of CA-MRSA have been more frequent in other parts of Canada and CMRSA-10 may be more pervasive in these communities. ${ }^{2,33}$ As the epidemiology of CA-MRSA is continually evolving, this study is reflective of the current situation in the Greater Toronto Area.

\section{CONCLUSION}

CA-MRSA is a significant cause of SSTIs in Toronto, and can affect patients without known communityrelated risk factors. Epidemiological risk factors may not distinguish between MSSA and MRSA or between CA-MRSA and hospital-associated MRSA. Despite extensive research conducted in this area, ${ }^{11,12}$ the most appropriate treatment for CA-MRSA remains unclear.

Acknowledgment: Heather Adam and Vanessa Allen contributed equally to the writing and revising of this manuscript.

Competing interests: Supported by a research grants from Physician Services Incorporated and an unrestricted educational grant from Wyeth Canada.

\section{REFERENCES}

1. Barton M, Hawkes M, Moore D, et al. Guidelines for the prevention and management of community-associated methicillin-resistant Staphylococcus aureus (CA-MRSA): a perspective for Canadian health care practitioners. Can 7 Infect Dis Med Micro 2006;17(Suppl C):1B-24B.

2. Gilbert M, MacDonald J, Gregson D, et al. Outbreak in alberta of community-acquired (USA300) methicillinresistant Staphylococcus aureus in people with a history of drug use, homelessness or incarceration. CMAJ 2006;175:149-54.

3. Groom AV, Wolsey DH, Naimi TS, et al. Communityacquired methicillin-resistant Staphylococcus aureus in a rural American Indian community. JAMA 2001; 286:1201-5.

4. Kaplan SL, Hulten K, Gonzalez B, et al. Three-year surveillance of community-acquired Staphylococus aureus infections in children. Clin Infect Dis 2005;40:1785-91. 
5 Kazakova S, Hageman J, Matava M, et al. A clone of methicillin-resistant Staphylococcus aureus among professional football players. N Engl 7 Med 2005;352:468-75.

6. Lee NE, Taylor MM, Bancroft E, et al. Risk factors for community-associated methicillin-resistant Staphylococcus aureus skin infections among $\mathrm{HIV}$-positive men who have sex with men. Clin Infect Dis 2005;40:1529-34.

7. Main CL, Jayarante P, Haley A, et al. Outbreaks of infection caused by community-acquired methicillin-resistant Staphylococcus aureus in a Canadian correctional facility. Can 7 Infect Dis Med Microbiol 2005;16:343-8.

8. Mathews WC, Caperna J, Barber R, et al. Incidence of and risk factors for clinically significant methicillin-resistant Staphylococcus aureus infection in a cohort of HIV-infected adults. J Acquir Immune Defic Syndr 2005;40:155-60.

9. Rosenthal A, White D, Churilla S, et al. Optimal surveillance culture sites for detection of methicillin-resistant Staphylococcus aureus in newborns. 7 Clin Microbiol 2006;44:4234-6.

10. Zinderman CE, Conner B, Malakooti MA, et al. Communityacquired methicillin-resistant Stapbylococcus aureus among military recruits. Emerg Infect Dis 2004;10:941-4.

11. Ruhe J, Smith N, Menon A, et al. Significance of antibiotic therapy for the treatment of community-onset methicillinresistant Staphylococcus aureus skin and soft-tissue infections. Interscience Conference on Antimicrobial Agents and Chemotherapy; 2006 September 27-30; San Francisco (CA): American Society for Microbiology.

12. Moran GJ, Krishnadasan A, Gorwitz RJ, et al. Methicillinresistant $S$. aureus infections among patients in the emergency department. N Engl J Med 2006;355:666-74.

13. Weese JS, Rousseau J, Willey B, et al. Methicillin-resistant Staphylococcus aureus in horses at a veterinary teaching hospital: frequency, characterization, and association with clinical disease. 7 Vet Intern Med 2006;20:182-6.

14. Kurbis C, Wylie J. Community-based cluster of methicillinresistant Staphylococcus aureus in Manitoba. Can 7 Infect Dis 2001;12:149-52.

15. McGeer A, Fleming C, Green K, et al. Antimicrobial resistance in common hospital pathogens in Ontario. QMPLS News 2007;116:1-12.

16. Surveillance for methicillin-resistant Staphylococcus aureus (MRSA) 2006 Results. Ottawa (ON): Canadian Nosocomial Infection Surveillance Program (CNISP); 2006. Available: www.phac-aspc.gc.ca/nois-sinp/projects/pdf/mrsa_report2006 -eng.pdf (accessed 2009 July 28).

17. Naimi TS, LeDell KH, Como-Sabetti K, et al. Comparison of community- and health care-associated methicillin-resistant Staphylococcus aureus infection. JAMA 2003;290:2976-84.

18. Labandeira-Rey M, Couzon F, Boisset S, et al. Staphylococcus aureus Panton-Valentine leukocidin causes necrotizing pneumonia. Science 2007;315:1130-3.

19. Popovich K, Hota B, Rice T, et al. Phenotypic prediction rule for community-associated methicillin-resistant Staphylococcus aureus. 7 Clin Microbiol 2007;45:2293-5.

20. Clinical and Laboratory Standards Institute. Performance standards for antimicrobial susceptibility testing. 17 th informational supplement. m100-s17. Wayne (PA): The Institute; 2007.

21. Clinical and Laboratory Standards Institute. Methods for dilution antimicrobial susceptibility tests for bacteria that grow aerobically. M7-A7. Wayne (PA): The Institute; 2006.

22. Fuchs PC, Jones RN, Barry AL. Interpretive criteria for disk diffusion susceptibility testing of mupirocin, a topical antibiotic. J Clin Microbiol 1990;28:608-9.

23. Toma E, Barriault D. Antimicrobial activity of fusidic acid and disk diffusion susceptibility testing criteria for gram-positive cocci. 7 Clin Microbiol 1995;33:1712-5.

24. Mulvey MR, Chui L, Ismail J, et al. Development of a Canadian standardized protocol for subtyping methicillin-resistant Staphylococcus aureus using pulsed-field gel electrophoresis. J Clin Microbiol 2001;39:3481-5.

25. Lina G, Piemont Y, Godail-Gamot F, et al. Involvement of panton-valentine leukocidin-producing Staphylococcus aureus in primary skin infections and pneumonia. Clin Infect Dis 1999;29:1128-32.

26. Oliveira DC, de Lencastre H. Multiplex PCR strategy for rapid identification of structural types and variants of the MEC element in methicillin-resistant Stapbylococcus aureus. Antimicrob Agents Chemother 2002;46:2155-61.

27. Willey B, Wong H, Louie L, et al. Editors. Comparison of two strategies for staphylococcal cassette chromosome mec (sccmec) typing in methicillin-resistant Staphylococcus aureus. San Francisco, (CA): 46th Interscience Conference on Antimicrobial Agents and Chemotherapy; 2006 September 27-30.

28. Seybold U, Kourbatova EV, Johnson JG, et al. Emergence of community-associated methicillin-resistant Staphylococcus aureus USA300 genotype as a major cause of health careassociated blood stream infections. Clin Infect Dis 2006;42: 647-56.

29. Lee MC, Rios AM, Aten MF, et al. Management and outcome of children with skin and soft tissue abscesses caused by community-acquired methicillin-resistant Staphylococcus aureus. Pediatr Infect Dis J 2004;23:123-7.

30. Rajendran PM, Young D, Maurer T, et al. Randomized, double-blind, placebo-controlled trial of cephalexin for treatment of uncomplicated skin abscesses in a population at risk for community-acquired methicillin-resistant Staphylococcus aureus infection. Antimicrob Agents Chemother 2007;51:4044-8.

31. Diep BA, Chambers HF, Graber CJ, et al. Emergence of multidrug-resistant, community-associated, methicillin-resistant Staphylococcus aureus clone USA300 in men who have sex with men. Ann Intern Med 2008;148:249-57.

32. Talan DA, Moran GJ, Mower WR, et al. Emergency ID net: an emergency department-based emerging infections sentinel network. The emergency ID net study group. Ann Emerg Med 1998;32:703-11.

33. Mulvey MR, MacDougall L, Cholin B, et al. Communityassociated methicillin-resistant Staphylococcus aureus, Canada. Emerg Infect Dis 2005;11:844-50.

Correspondence to: Dr. Kevin Katz, Department of Laboratory Medicine, North York General Hospital, Toronto ON M2K 1E1; kkatz@nygh.on.ca 